\title{
Neutral Heteroatomic Components in Thermohydrolytic Processing Products of Sapropelites
}

\author{
V.Yu. Rokosova, P.V. Goryunova, Yu.V. Rokosov, N.N. Rokosova
}

\begin{abstract}
Neutral heteroatomic components obtained during processing of Kushmurun (Kazakhstan) and Maoming (China) sapropelites in autoclaves under conditions of oxidative-hydrolytic destruction of their organic mass were studied using chromatographic-mass spectrometry and chemical informatics methods. Neutral oxygen-containing components in the products of thermohydrolytic processing of Kushmurun coal and Maoming oil shale are mainly represented by alkylmethylketones of normal structure (up to 60\%) in the distribution ranges from $C_{10}$ to $C_{25}$. In smaller quantities, arylalkylketones (up to $10 \%$ ), alkylphenols (up to $22 \%$ ) and indanols (up to 7\%) are identified. The appreciable content of alkyl aromatic compounds, characteristic for the samples of sapropelites studied, is apparently due to a peculiar diagenetic aromatization of the sapropelic starting material. The obtained results showed that the method of thermohydrolysis of sapropelites is quite suitable for elucidating their structural features caused by processes of diagenetic or catagenetic aromatization.
\end{abstract}

Index Terms - sapropelites, thermohydrolytic processing products, neutral heteroatomic components, alkylmethylketones, arylalkylketones, alkylphenols, indanols.

\section{INTRODUCTION}

In the work to which this article is devoted, the objects of research were thermohydrolysis products of hydrocarbon-generating rocks (sapropelite coals and oil shales) that were studied for the composition, content, structural features, molecular distribution of constituent organic components - neutral heteroatomic compounds. The hydrocarbon compounds in the products of the thermohydrolysis of sapropelites were investigated earlier [1-4].

V.Yu. Rokosova, Institute of Coal Chemistry and Chemical Materials Science of the Federal State Budget Scientific Institution "The Federal Research Center of Coal and Coal Chemistry of Siberian Branch of the Russian Academy of Sciences", 18 Sovetskiy Prospect, Kemerovo, 650003, Russia,

P.V. Goryunova, Institute of Coal Chemistry and Chemical Materials Science of the Federal State Budget Scientific Institution "The Federal Research Center of Coal and Coal Chemistry of Siberian Branch of the Russian Academy of Sciences", 18 Sovetskiy Prospect, Kemerovo, 650003, Russia

Yu.V. Rokosov, Institute of Coal Chemistry and Chemical Materials Science of the Federal State Budget Scientific Institution "The Federal Research Center of Coal and Coal Chemistry of Siberian Branch of the Russian Academy of Sciences", 18 Sovetskiy Prospect, Kemerovo, 650003, Russia

N.N. Rokosova, Institute of Coal Chemistry and Chemical Materials Science of the Federal State Budget Scientific Institution "The Federal Research Center of Coal and Coal Chemistry of Siberian Branch of the Russian Academy of Sciences", 18 Sovetskiy Prospect, Kemerovo, 650003, Russia
The problem of developing effective processes for deep processing of sapropelite coals and oil shales as non-traditional hydrocarbon raw materials is caused by the public demand for petrochemical products. Despite the recent rise in prices for crude oil, the deep processing of these hydrocarbon-producing rocks did not become a reality on a scale that could be expected. The calculation should be carried out taking into account that the world reserves of sapropelite oil shale in translation for the oil equivalent are no less than ten times higher than the reserves of traditional oil and natural gas. The reserves of oil shales are estimated at hundreds of billions of tons, and the largest deposits of sapropelite coals are only tens of millions of tons. There are no significant genetic differences between the organic mass of such coals and shales, although shale-processing results in larger-scale environmental problems in the utilization of organomineral waste.

According to academician Aleksey Kontorovich, - the chairman of the Scientific Council of the Russian Academy of Sciences on the problems of geology and development of oil and gas fields, the active phase of processing unconventional hydrocarbon raw materials around the world will begin in the second half of the 21 st century [5]. According to his forecasts, the traditional oil production, carried out now, will reach a peak in the 30s - 40s of this century. According to the most optimistic forecasts, the traditional oil production will reach a peak in the $60 \mathrm{~s}-70 \mathrm{~s}$. After that, the industry will start shifting to the production and processing of shale oil. The prospects for the transition of the industry to shale raw materials are highly dependent on the quality of new developments.

On the basis of the foregoing, the relevance of the topic of the studies discussed here is related to the need to determine (in the ideal case of monitoring) the molecular composition of complex mixtures of pyrogenic compounds for the development of high-tech methods for processing coal and oil shales into products for industrial organic synthesis.

Objective studies was to establish the composition and content of neutral heteroatomic components formed during processing sapropelites in autoclaves under the oxidation-hydrolytic degradation [1] of the organic mass. The fractions of neutral heteroatomic components were isolated from the products of thermohydrolysis of sapropelite coal from the Kushmurun deposit of the Turgai basin of Kazakhstan (ash content 29.2\%, composition of the combustible mass, \% C 72.1, H 9.5, N 3.4, S 0.7, O 14.3) and of oil shale from Maoming deposits of China (ash content 
73.7\%, composition of combustible mass, \%: C 79.4, H 9.6, N 1.0, S 1.7, O 8.3).

\section{EXPERIMENTAL}

The test samples were crushed and milled sequentially on screw and washer mills until the entire sample was sieved through a $0.2 \mathrm{~mm}$ sieve. Part of the sample was separated for technical and elemental analyzes. The sample prepared for the study was stored in a closed glass jar.

Products of thermohydrolysis of sapropelite were obtained in a rotating autoclave made of steel IX18H10T with a volume of 0.5 liters, equipped with a thermocouple, a high pressure valve and a manometer. We loaded $10 \mathrm{~g}$ of the test sample and $300 \mathrm{ml}$ of a $5 \%$ aqueous solution of $\mathrm{KOH}$ into the autoclave. The autoclave was filled with gaseous nitrogen (5 $\mathrm{MPa}$ ) and heated in an electric furnace to a temperature of $400^{\circ} \mathrm{C}$ over $50-60 \mathrm{~min}$ while being rotated (200 min-1). The temperature in the autoclave was kept to within \pm 2 deg from the specified value for $1 \mathrm{~h}$. The autoclave was then cooled to $40^{\circ} \mathrm{C}$ while the contents were being agitated and was then unloaded. The products were removed from the autoclave, and the solid part was filtered off on a glass filter. The deposit on the filter was washed with diethyl ether $(150 \mathrm{ml})$. The neutral thermohydrolysis products were separated from the filtrate by extraction from the alkaline solution with diethyl ether. After neutralization with $2 \%$ hydrochloric acid solution the products soluble in aqueous alkali were extracted with diethyl ether. The mixtures of neutral and acidic compounds thus obtained were combined before chromatography on a column of silica gel impregnated with KOH. Some thermohydrolytic products $(0.45 \mathrm{~g})$ were dissolved in a small amount of diethyl ether, placed on a silica gel column and eluted with diethyl ether $(300-350 \mathrm{ml})$ to separate the neutral compounds.

The contents of the fractions in the products from thermohydrolytic processing of the sapropelites are presented in Table 1.

The fractions were analyzed on an Agilent 6890N chromatograph with a 5973 mass-selective detector. Separation conditions: carrier gas helium; HP-5MS column, $30 \mathrm{~m} \times 0.25 \mathrm{~mm}$; evaporator temperature $250^{\circ} \mathrm{C}$; column temperature increasing from $50^{\circ} \mathrm{C}(3 \mathrm{~min})$ to $250^{\circ} \mathrm{C}$ at 2 $\mathrm{deg} / \mathrm{min}$, holding time $2 \mathrm{~h}$ at $250^{\circ} \mathrm{C}$. The energy of the ionizing electrons was $70 \mathrm{eV}$. The heteroatomic components were identified by means of their mass spectra from the AMDIS and ChemStation data systems.

Table 1. Comparative results of chromatographic separation of the fractions obtained from the sapropelites

\begin{tabular}{|c|c|c|c|}
\hline \multirow{2}{*}{$\begin{array}{l}\text { Sapropelite } \\
\text { (coal or oil shale) }\end{array}$} & \multicolumn{3}{|c|}{ Content of fraction, $\%$, calculated on the organic mass of coal or oil shale } \\
\hline & paraffin-naphthenic & neutral heteroatomic & acidic heteroatomic \\
\hline Kushmurun & 9,7 & 20,8 & 29,3 \\
\hline Maoming & 5,9 & 22,8 & 15,2 \\
\hline
\end{tabular}

\section{RESULTS AND DiSCUSSION}

Chromatograms of neutral heteroatomic components isolated from the products of thermohydrolysis of sapropelites contain mainly groups of peaks related to n-alkylketones, alkylphenols, arylalkylketones, and indanols. It was also found that the products of thermohydrolysis of sapropelites also contain nitrogen-containing compounds. In addition to these groups of compounds, the presence of other components - tetrahydronaphthalene ethers, saturated and monounsaturated alkylaldehydes, and bifunctional carbonyl-containing aliphatic compounds of complex structure is detected by chromatography-mass spectrometry. The results of determining the relative contents of the listed groups of compounds are shown in Table 2.

Table 2. Content of neutral heteroatomic components in fractions obtained from coal/oil shale

\begin{tabular}{|l|c|c|}
\hline \multirow{2}{*}{ Heteroatomic components } & \multicolumn{2}{|c|}{ Content, \% } \\
\cline { 2 - 3 } & Kushmurun coal & Maoming oil shale \\
\hline n-Alkylketones & 60,34 & 43,71 \\
Arylalkylketones & 4,09 & 9,78 \\
Alkylphenols & 11,33 & 22,11 \\
Indanols & 4,50 & 7,04 \\
Nitrogen-containing & 5,27 & 7,10 \\
Other & 14,47 & 10,26 \\
\hline
\end{tabular}

Alkylmethylketones of the normal structure are the most common among the neutral heteroatomic components in the thermohydrolysates of the sapropelites studied. Mass-chromatograms of mixtures of these components in the case of each of the samples studied contain a homology series of n-alkylmethylketones reliably identified by mass spectra Among the oxygen-containing groups, methylketone structures predominate. The fractions of alkylketones also contain branched (isoprenoid) compounds 5,9-dimethyldecan-2-one and 6,10-dimethylundecan-2-one $(0,84 \%$ and $1,05 \%$, respectively) in the case of Kushmurun coal, and 6,10,14-trimethylpentadecane-2-one $(1,58 \%)$ in the 
case of Maoming oil shale. In addition to alkylmethyl ketones, undecan-6-one (6,09 and 0,62\% for the Kushmurun and Maoming samples, respectively), tridecane-6-one $(1,46 \%$, Kushmurun), hexadecan-3-one (1,77\%, Kushmurun) and octadecan-3-one (1,39\%, Kushmurun) were found.
The results of the study of alkylphenols in the composition of heteroatomic components isolated from oxidation-hydrolytic decomposition products of the organic mass of sapropelites are presented in Tables 3 and 4 .

Table 3. Results of identification of alkylphenols in the composition of products obtained by thermohydrolysis treatment of Kushmurun coal

\begin{tabular}{|c|c|c|c|c|}
\hline No. & Component & Formula & $\begin{array}{l}\text { Time output, } \\
\text { minutes }\end{array}$ & $\begin{array}{c}\text { Relative content, } \\
\%\end{array}$ \\
\hline 1 & $\begin{array}{l}\text { 2-Methylphenol } \mathrm{C}_{7} \mathrm{H}_{8} \mathrm{O} \\
\text { (M.в. 108) }\end{array}$ & & 17,05 & 0,84 \\
\hline 2 & $\begin{array}{l}\text { 3- Methylphenol } \mathrm{C}_{7} \mathrm{H}_{8} \mathrm{O} \\
\text { (M.в. 108) }\end{array}$ & & 18,42 & 1,66 \\
\hline 3 & $\begin{array}{l}\text { 4- Methylphenol } \mathrm{C}_{7} \mathrm{H}_{8} \mathrm{O} \\
\text { (M.в. 108) }\end{array}$ & & 19,02 & 0,48 \\
\hline 4 & $\begin{array}{l}\text { 3-Ethylphenol } \mathrm{C}_{8} \mathrm{H}_{10} \mathrm{O} \\
\text { (M.в. 122) }\end{array}$ & & 24,32 & 0,74 \\
\hline 5 & $\begin{array}{l}\text { 3,5-Dimethylphenol } \mathrm{C}_{8} \mathrm{H}_{10} \mathrm{O} \\
\text { (M.в. 122) }\end{array}$ & & 24,48 & 1,92 \\
\hline 6 & $\begin{array}{l}\text { 3-Ethyl-5-methylphenol } \mathrm{C}_{9} \mathrm{H}_{12} \mathrm{O} \\
\text { (M.в. 136) }\end{array}$ & & 30,47 & 1,75 \\
\hline 7 & $\begin{array}{l}\text { 2-Allyl-4-methylphenol } \\
\mathrm{C}_{10} \mathrm{H}_{12} \mathrm{O} \text { (М.в. 148) }\end{array}$ & & 42,08 & 3,28 \\
\hline 8 & $\begin{array}{l}\text { 2- } n \text {-Hexylphenol } \mathrm{C}_{12} \mathrm{H}_{18} \mathrm{O} \\
\text { (M.в. 178) }\end{array}$ & & 46,53 & 0,66 \\
\hline
\end{tabular}

Thus, the presence of aromatic structural units in the organic mass of the investigated sapropelites is well manifested in the chromatographic-mass spectrometric analysis of the products of their oxidative-hydrolytic degradation in an alkaline medium. The maximum yield of alkylphenols was just over $22 \%$ of the organic matter of sapropelite.

The indanol fractions in the case of the Kushmurun and Maoming samples contain the same components - 5-indanol $(3,47$ and 5,64\%, respectively) and 6-methyl-4-indanol (1,03 and $1,40 \%)$.

In fractions of nitrogen-containing compounds, 1-aminoindane (2,51 and 1,92\%), 2,7-dimethylquinoline $(0,85$ and $1,09 \%)$ and 2,4-dimethylquinoline $(0,85$ and $1,38 \%)$. In addition, in the case of the Kushmurun sample, the presence of $\mathrm{N}$-phenylaniline $(1,06 \%)$ and, in the case of Maoming, 2,3,4-trimethylquinoline $(0,35 \%)$ was detected.

The results of the investigation of arylalkylketones in the composition of heteroatomic components are presented in Tables 5 and 6 .

Figure 1 presents data on the composition and regularities of the distribution of $n$-alkylmethylketones in fractions of neutral heteroatom components isolated from products of oxidative-hydrolytic destruction of the organic mass of oil shale and sapropelite coal

The pattern of the distribution of n-alkylmethylketones in the case of Maoming shale is characterized by the presence of well-defined maxima of $\mathrm{C}_{15}$ and $\mathrm{C}_{17}$. In the case of the Kushmurun sample, the maximum contents are observed for the $\mathrm{C}_{15}$ and $\mathrm{C}_{19}$ ketones, but they are not so pronounced, which may indicate a greater catagenetic transformation of the organic mass of this coal compared to the organic matter of the shale investigated. However, this clearly contradicts the petrographic data, according to which the organic mass of the Kushmurun sample refers to the brown coal carbonization stage, and the organic matter of the Maoming shale is to the long-flame stage. Perhaps the petrographic data are not accurate and the organic matter of the Kushmurun sapropelite has also been converted to a long-term carbonization stage. The latter assumption is also supported by the fact that the data for the Kushmurun sapropelite do not fit, as noted by the authors [8], in the regularity of the increase in the content of neutral oxygen-containing compounds as the lithogenetic maturity of the organic mass increases. 
Table 4. Results of identification of alkylphenols in the composition of products obtained by thermohydrolysis treatment of Maoming oil shale

\begin{tabular}{|c|c|c|c|c|}
\hline No. & Component & Formula & $\begin{array}{c}\text { Time output, } \\
\text { minutes }\end{array}$ & $\begin{array}{c}\text { Relative content, } \\
\% \\
\end{array}$ \\
\hline 1 & $\begin{array}{l}\text { 2- Methylphenol } \mathrm{C}_{7} \mathrm{H}_{8} \mathrm{O} \\
\text { (M.в. 108) }\end{array}$ & & 17,07 & 0,85 \\
\hline 2 & $\begin{array}{l}\text { 3- Methylphenol } \mathrm{C}_{7} \mathrm{H}_{8} \mathrm{O} \\
\text { (M.в. 108) }\end{array}$ & & 18,43 & 3,57 \\
\hline 3 & $\begin{array}{l}\text { 4- Methylphenol } \mathrm{C}_{7} \mathrm{H}_{8} \mathrm{O} \\
\text { (M.в. 108) }\end{array}$ & & 19,03 & 0,36 \\
\hline 4 & $\begin{array}{l}\text { 2,4-Dimethylphenol } \mathrm{C}_{8} \mathrm{H}_{10} \mathrm{O} \\
\text { (M.в. 122) }\end{array}$ & & 23,05 & 0,56 \\
\hline 5 & $\begin{array}{l}\text { 3-Ethylphenol } \mathrm{C}_{8} \mathrm{H}_{10} \mathrm{O} \\
\text { (M.в. 122) }\end{array}$ & & 24,34 & 0,76 \\
\hline 6 & $\begin{array}{l}\text { 3,5- Dimethylphenol } \mathrm{C}_{8} \mathrm{H}_{10} \mathrm{O} \\
\text { (M.в. 122) }\end{array}$ & & 24,48 & 3,63 \\
\hline 7 & $\begin{array}{l}\text { 2,3- Dimethylphenol } \mathrm{C}_{8} \mathrm{H}_{10} \mathrm{O} \\
\text { (M.в. 122) }\end{array}$ & & 24,98 & 0,89 \\
\hline 8 & $\begin{array}{l}\text { 2- Ethylphenol } \mathrm{C}_{8} \mathrm{H}_{10} \mathrm{O} \\
\text { (M.в. 122) }\end{array}$ & & 26,05 & 0,65 \\
\hline 9 & $\begin{array}{l}\text { 3-Isopropylphenol } \mathrm{C}_{9} \mathrm{H}_{12} \mathrm{O} \\
\text { (M.в. 136) }\end{array}$ & & 28,53 & 0,62 \\
\hline 10 & $\begin{array}{l}\text { 2-Ethyl-5-methylphenol } \mathrm{C}_{9} \mathrm{H}_{12} \mathrm{O} \\
\text { (M.в. 136) }\end{array}$ & & 29,01 & 0,38 \\
\hline 11 & $\begin{array}{l}\text { 2-Ethyl-6-methylphenol } \mathrm{C}_{9} \mathrm{H}_{12} \mathrm{O} \\
\text { (M.в. 136) }\end{array}$ & & 29,28 & 0,27 \\
\hline 12 & $\begin{array}{l}\text { 3-Ethyl-5-methylphenol } \mathrm{C}_{9} \mathrm{H}_{12} \mathrm{O} \\
\text { (M.в. 136) }\end{array}$ & & 30,49 & 2,64 \\
\hline 13 & $\begin{array}{l}\text { 2,3,6-Trimethylphenol } \mathrm{C}_{9} \mathrm{H}_{12} \mathrm{O} \\
\text { (M.в. 136) }\end{array}$ & & 31,11 & 0,65 \\
\hline 14 & $\begin{array}{l}\text { 2,5-Diethylphenol } \mathrm{C}_{10} \mathrm{H}_{14} \mathrm{O} \\
\text { (М.в. 150) }\end{array}$ & & 34,22 & 0,62 \\
\hline 15 & $\begin{array}{l}\text { 2-Methyl-6-propylphenol } \mathrm{C}_{10} \mathrm{H}_{14} \mathrm{O} \\
\text { (M.в. 150) }\end{array}$ & & 34,75 & 0,25 \\
\hline 16 & $\begin{array}{l}\text { 2-Allyl-6-methylphenol } \mathrm{C}_{10} \mathrm{H}_{12} \mathrm{O} \\
\text { (M.в. 148) }\end{array}$ & & 40,77 & 0,91 \\
\hline 17 & $\begin{array}{l}\text { 2-Allyl-4-methylphenol } \mathrm{C}_{10} \mathrm{H}_{12} \mathrm{O} \\
\text { (M.в. 148) }\end{array}$ & & 42,06 & 3,61 \\
\hline 18 & $\begin{array}{l}\text { 4- [3-Methyl-2-butenyl] phenol } \mathrm{C}_{10} \mathrm{H}_{18} \mathrm{O} \\
\text { (M.в. 162) }\end{array}$ & & 42,85 & 0,89 \\
\hline
\end{tabular}


Table 5. Results of identification of arylalkyl ketones in the composition of heteroatomic components obtained by thermohydrolysis treatment of Kushmurun coal

\begin{tabular}{|c|c|c|c|c|}
\hline No. & Component & Formula & $\begin{array}{l}\text { Time output, } \\
\text { minutes }\end{array}$ & $\begin{array}{c}\text { Relative content, } \\
\%\end{array}$ \\
\hline 1 & $\begin{array}{l}\text { 4-Ethyl acetophenone } \mathrm{C}_{10} \mathrm{H}_{12} \mathrm{O} \\
\text { (M.в. 148) }\end{array}$ & & 37,06 & 0,81 \\
\hline 2 & $\begin{array}{l}\text { 3,6-Dimethylacetophenone } \mathrm{C}_{10} \mathrm{H}_{12} \mathrm{O} \\
\text { (M.в. 148) }\end{array}$ & & 38,51 & 0,96 \\
\hline 3 & $\begin{array}{l}\text { 2-Ethyl acetophenone } \mathrm{C}_{10} \mathrm{H}_{12} \mathrm{O} \\
\text { (М.в. 148) }\end{array}$ & & 40,09 & 1,63 \\
\hline 4 & $\begin{array}{l}\text { 4-Isopropylacetophenone } \mathrm{C}_{11} \mathrm{H}_{14} \mathrm{O} \\
\text { (M.в. 162) }\end{array}$ & & 45,79 & 0,69 \\
\hline
\end{tabular}

Table 6. Results of the identification of arylalkyl ketones in the composition of heteroatomic components obtained by thermohydrolysis treatment of Maoming oil shale

\begin{tabular}{|c|c|c|c|c|}
\hline No. & Component & Formula & $\begin{array}{l}\text { Time output, } \\
\text { minutes }\end{array}$ & $\begin{array}{c}\text { Relative content, } \\
\%\end{array}$ \\
\hline 1 & $\begin{array}{l}\text { 2,4-Dimethylacetophenone } \mathrm{C}_{10} \mathrm{H}_{12} \mathrm{O} \\
\text { (M.в. 148) }\end{array}$ & & 36,19 & 0,69 \\
\hline 2 & $\begin{array}{l}\text { 3-Ethyl acetophenone } \mathrm{C}_{10} \mathrm{H}_{12} \mathrm{O} \\
\text { (M.в. 148) }\end{array}$ & & 36,58 & 0,28 \\
\hline 3 & $\begin{array}{l}\text { 4-Ethyl acetophenone } \mathrm{C}_{10} \mathrm{H}_{12} \mathrm{O} \\
\text { (M.в. 148) }\end{array}$ & & 37,04 & 0,60 \\
\hline 4 & $\begin{array}{l}\text { 3,6-Dimethylacetophenone } \mathrm{C}_{10} \mathrm{H}_{12} \mathrm{O} \\
\text { (M.в. 148) }\end{array}$ & & 38,48 & 0,27 \\
\hline 5 & $\begin{array}{l}\text { 3,4-Dimethylacetophenone } \mathrm{C}_{10} \mathrm{H}_{12} \mathrm{O} \\
\text { (M.в. 148) }\end{array}$ & & 38,62 & 0,48 \\
\hline 6 & $\begin{array}{l}\text { 2-Ethyl acetophenone } \mathrm{C}_{10} \mathrm{H}_{12} \mathrm{O} \\
\text { (M.в. 148) }\end{array}$ & & 40,08 & 1,07 \\
\hline 7 & $\begin{array}{l}\text { 4-Isopropylacetophenone } \mathrm{C}_{11} \mathrm{H}_{14} \mathrm{O} \\
\text { (M.в. 162) }\end{array}$ & & 45,77 & 0,46 \\
\hline
\end{tabular}




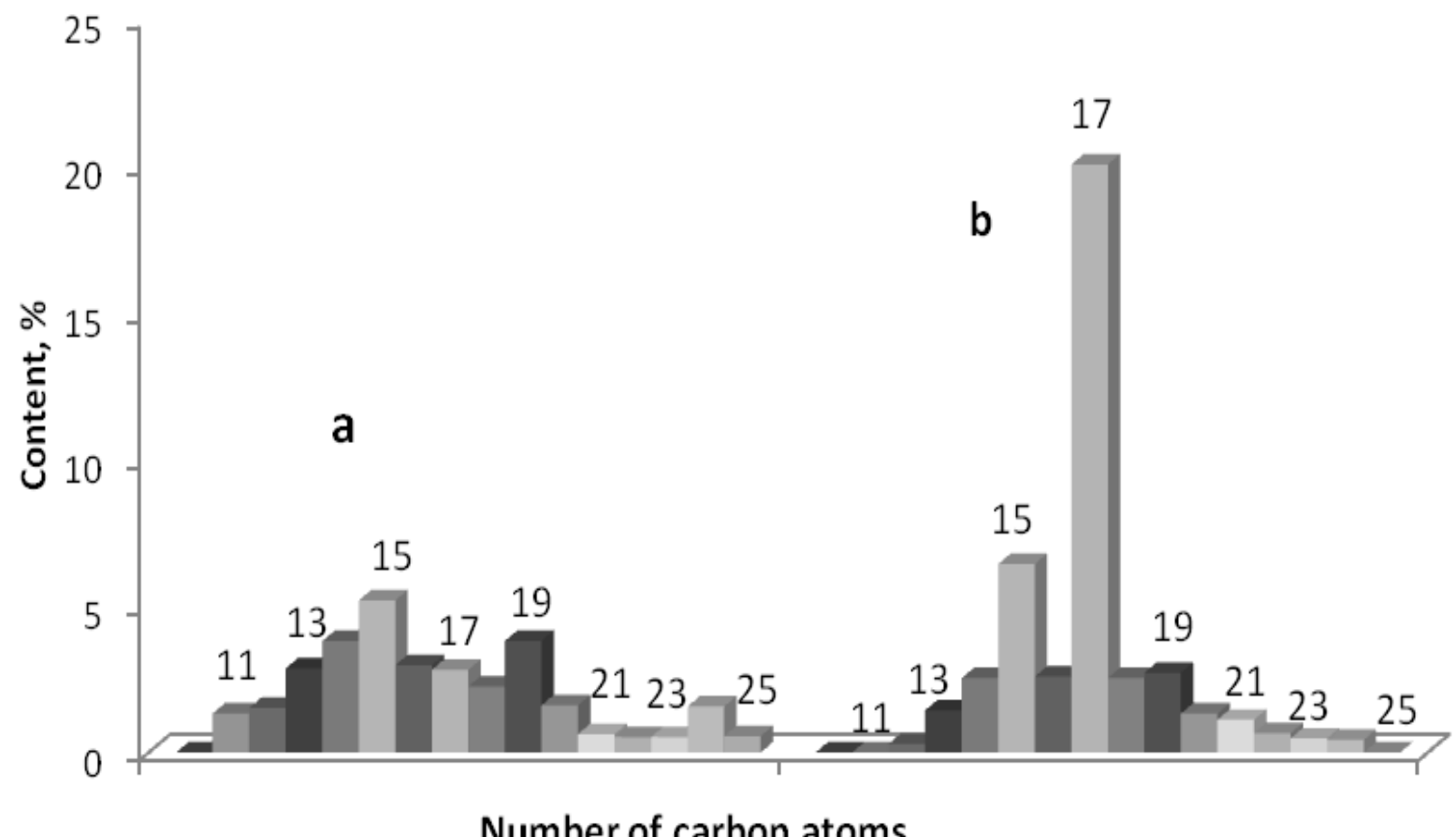

Fig. 1. Dependence of the content of n-alkylmethylketones $\mathrm{C}_{10}-\mathrm{C}_{25}$ on the number of carbon atoms in the molecule in the case of Kushmurun coal (a) and Maoming shale (b).

\section{CONCLUSSION}

Judging by the results obtained, the main neutral heteroatomic components generated by the organic mass of the investigated sapropelites under oxidative-hydrolytic processing conditions are normal-structure alkylmethylketones (up to $60 \%$ ) in the $\mathrm{C}_{10}$ to $\mathrm{C}_{25}$ distribution ranges. In smaller quantities, arylalkylketones (up to $10 \%$ ), alkylphenols (up to 22\%) and indanol (up to 7\%) are identified. The appreciable content of alkylaromatic compounds, characteristic for the samples of sapropelites studied, is apparently due to a peculiar diagenetic aromatization of the sapropelic starting material. The obtained results showed that the method of thermohydrolysis of sapropelites is quite suitable for elucidating their structural features caused by processes of diagenetic or catagenetic aromatization.

\section{ACKNOWLEDGMENT}

This work was conducted within the framework of the budget project AAAA-A17-117041910147-2 for the Institute of Coal Chemistry and Chemical Material Science of FRC CCC SB RAS.

The authors are grateful to Cand. Chem. Sci. V. I. Rodionov (Novosibirsk Institute of Organic Chemistry, Siberian Branch, Russian Academy of Sciences, Novosibirsk) for assistance in the experiments on the thermohydrolytic transformation of sapropelites.

Chromato-mass-spectrometric studies were performed using the equipment of the Center for Collective Use of Scientific Equipment of FRC CCC SB RAS.

\section{REFERENCES}

[1] Rokosova N.N., Rokosova V.Yu., Rokosov Yu.V. Hydrocarbons in the Aqueous-Pyrolysis Products of Mongolian Fuel Shales and Bituminous Rock // Coke and Chemistry. 2014. V. 57. N. 12. P. 485-488.

[2] Rokosova V.Yu., Lapsina P.V., Rokosov Yu.V., Rokosova N.N., Moiseev A.I., Sozinov S.A. Hydrocarbons and Carboxylic Acids in the Products of Thermohydrolysis of Sapropelites of Kuzbass [in Russian] // High Tech Development and Use of Mineral Resources: Sci. Journal / Sib. Gos. Industr. University; Ed. V.N. Frjanov. - Novokuznetsk, 2017. - N. 3. - P. 79-85.

[3] Rokosova V.Yu., Goryunova P.V., Rokosov Yu.V., Rokosova N.N., Sozinov S.A. Hydrocarbons in Products of Thermo-Hydrolytic Decomposition of Sapropelite [in Russian] // Chemistry for Sustainable Development. 2017. N. 6. P. 653-661.

[4] Rokosova V.Yu. Petroleum Generating Properties of Sapropelites. Investigation of Hydrocarbon-Generating Rocks by Methods of Hydropyrolysis, Thermohydrolysis and Spectral Analysis, Lap Lambert Academic Publishing, Beau Bassin, Mauritius, 2018, 180 pp.

[5] Rokosova N.N. Genesis of Sapropelic Coals and Their Properties during Pyrolysis. Principles of New Production Technologies for Shale Oil and Carbonaceous Materials [in Russian], Lap Lambert Academic Publishing, Saarbrucken, Germany, 2013, 288 pp.

[6] Kontorovich A.E. The Country Needs a Strong Program of Re-Industrialization on a New Technological Level [in Russian] // Burenie \& Neft. 2017. N. 7-8. P. 4-11.

[7] Rokosova N.N., Rokosova V.Yu., Rokosov Yu.V. Hydrocarbons in the Products of Oxidative-Hydrolytic Transformation of Sapropelites // Chemistry and Technology of Fuels and Oils. 2016. V. 52. N. 4. P. 402-408.

[8] Rokosov Yu.V., Rokosova N.N., Rokosova V.Yu. Content of Neutral Oxygen-Containing Compounds in the Products of Thermo-Hydrolysis of Sapropelite in Connection with the Lithogenetic Maturity of Their Organic Mass [in Russian] // Estestv. Tekhn. Nauki. 2016. N. 7. P. 23-27. 